\title{
VOF Calculations of Countercurrent Gas-Liquid Flow in a PWR Hot Leg
}

\author{
M. Murase, ${ }^{1}$ A. Tomiyama, ${ }^{2}$ I. Kinoshita, ${ }^{1,2}$ Y. Utanohara, ${ }^{1}$ Chihiro Yanagi, ${ }^{1}$ \\ T. Takata, ${ }^{3}$ and A. Yamaguchi ${ }^{3}$ \\ ${ }^{1}$ Institute of Nuclear Technology, Institute of Nuclear Safety System, Inc., 64 Sata, Mihama-cho, Mikata-gun, Fukui 919-1205, Japan \\ ${ }^{2}$ Department of Mechanical Engineering, Kobe University, 1-1 Rokkodai, Nada-ku, Kobe, 657-8501, Japan \\ ${ }^{3}$ Department of Sustainable Energy and Environmental Engineering, Osaka University, 2-1 Yamadaoka, Suita-shi, \\ Osaka 565-0871, Japan
}

Correspondence should be addressed to M. Murase, murase@inss.co.jp

Received 11 October 2011; Accepted 9 November 2011

Academic Editor: Deendarlianto

Copyright ( $) 2012$ M. Murase et al. This is an open access article distributed under the Creative Commons Attribution License, which permits unrestricted use, distribution, and reproduction in any medium, provided the original work is properly cited.

\begin{abstract}
We improved the computational grid and schemes in the VOF (volume of fluid) method with the standard $k-\varepsilon$ turbulent model in our previous study to evaluate CCFL (countercurrent flow limitation) characteristics in a full-scale PWR hot leg (750 mm diameter), and the calculated CCFL characteristics agreed well with the UPTF data at 1.5 MPa. In this paper, therefore, to evaluate applicability of the VOF method to different fluid properties and a different scale, we did numerical simulations for full-scale airwater conditions and the $1 / 15$-scale air-water tests $(50 \mathrm{~mm}$ diameter), respectively. The results calculated for full-scale conditions agreed well with CCFL data and showed that CCFL characteristics in the Wallis diagram were mitigated under $1.5 \mathrm{MPa}$ steam-water conditions comparing with air-water flows. However, the results calculated for the $1 / 15$-scale air-water tests greatly underestimated the falling water flow rates in calculations with the standard $k-\varepsilon$ turbulent model, but agreed well with the CCFL data in calculations with a laminar flow model. This indicated that suitable calculation models and conditions should be selected to get good agreement with data for each scale.
\end{abstract}

\section{Introduction}

Reflux condensation by steam generators (SGs) is considered as one of the possible core cooling methods under hypothetical accident conditions in pressurized water reactors (PWRs). In the reflux condensation, the steam generated in the core and the water condensed in the SG form a countercurrent flow in a hot leg, which consists of a horizontal pipe, an elbow and an inclined pipe. As reviewed by $\mathrm{Al}$ Issa and Macian [1], many experiments have been conducted to investigate the countercurrent flow limitation (CCFL) in the hot leg, and empirical correlations were proposed using Wallis parameters [2]. The review showed that many differences between CCFL data were simply due to geometrical effects. To compare CCFL characteristics in hot leg models, Vallée et al. [3] selected three geometrical factors, which were the horizontal pipe length to diameter ratio $\left(L_{H} / D\right)$, the inclined pipe length to diameter ratio $\left(L_{I} / D\right)$, and the elbow angle $\theta$. They showed that even for similar geometrical factors there was clear deviation between CCFL characteristics due to scale effects. Moreover, effects of fluid properties on CCFL characteristics in a hot leg have not been clearly discussed. Therefore, in order to evaluate effects of scale and fluid properties better, numerical simulation using CFD (computational fluid dynamics) software is expected to be useful.

In order to investigate effects of scale and fluid properties on CCFL characteristics in hot leg models, we have done numerical simulations using a two-fluid model and a VOF (volume of fluid) method implemented in the CFD software, FLUENT6.3.26. We found that the two-fluid model could reproduce CCFL characteristics under low pressure conditions and we confirmed that those in the hot leg could be well correlated with the Wallis parameters in the region of $50 \mathrm{~mm} \leq D \leq 750 \mathrm{~mm}[4]$. The two-fluid model, however, did not give good results for a large gas density. On the 


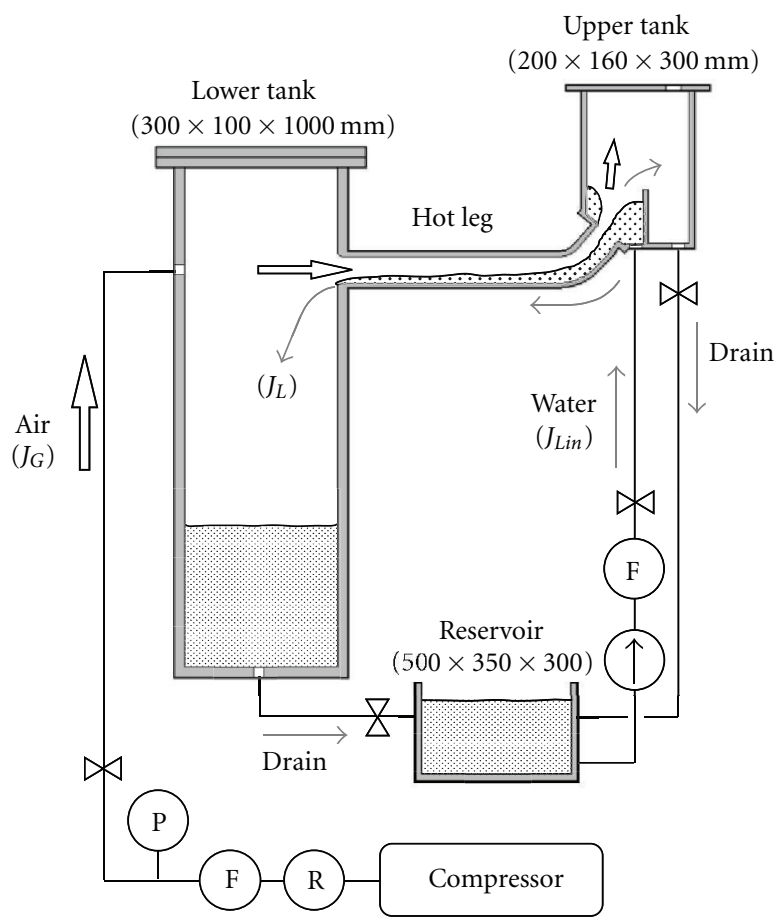

(a) Experimental apparatus

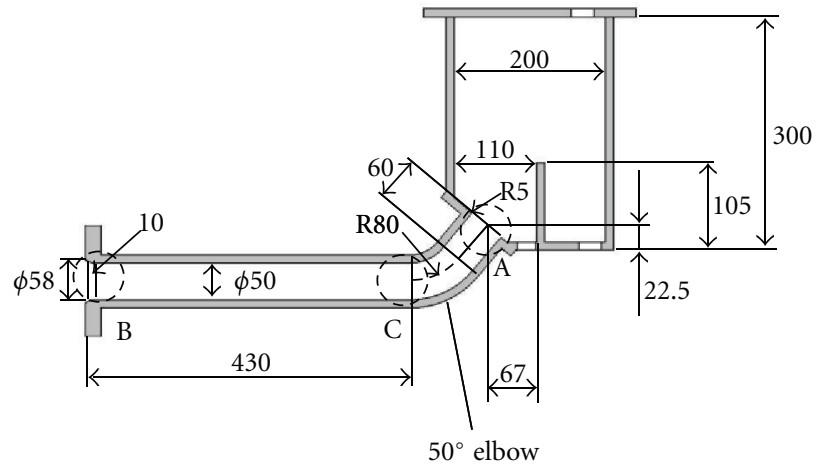

(A, B, and C: flooding locations)

(b) Teat section

Figure 1: Experimental apparatus and test section used by Minami et al. [8] (unit: mm).

other hand, the VOF method could reproduce the effects of fluid properties on CCFL characteristics in a rectangular channel [5], but could not simulate CCFL characteristics in a circular channel. Therefore, the computational grid and schemes were improved in the VOF method [6], and the CCFL characteristics calculated for full-scale conditions agreed well with the UPTF data [7] at 1.5 MPa.

In this paper, in order to evaluate applicability of the VOF method to different fluid properties and a different scale, we did numerical simulations using the VOF method employed in the previous study [6] for full-scale air-water conditions (750 $\mathrm{mm}$ diameter) and the $1 / 15$-scale air-water tests $(50 \mathrm{~mm}$ diameter) reported by Minami et al. [8], respectively.

\section{Summary of Previous Studies}

In this section, major results of previous studies are summarized and subjects of our own studies are described.

CCFL characteristics in a PWR hot leg are generally expressed by using the Wallis correlation or Wallis parameters which are, respectively, defined by [2]

$$
\begin{gathered}
\left(J_{G}^{*}\right)^{1 / 2}+m\left(J_{L}^{*}\right)^{1 / 2}=C \\
J_{k}^{*}=J_{k}\left\{\frac{\rho_{k}}{g \cdot \ell \cdot\left(\rho_{L}-\rho_{G}\right)}\right\}^{1 / 2} \\
\ell=D \text { or } H(k=G \text { or } L),
\end{gathered}
$$

where $J(\mathrm{~m} / \mathrm{s})$ is the volumetric flux in the hot leg, $m$ and $C$ are empirical constants, $\ell(\mathrm{m})$ is the characteristic length,
$D(\mathrm{~m})$ is the diameter of the hot leg, $H(\mathrm{~m})$ is the height of a hot leg model with a rectangular channel, $g\left(\mathrm{~m} / \mathrm{s}^{2}\right)$ is the gravity acceleration, and $\rho\left(\mathrm{kg} / \mathrm{m}^{3}\right)$ is the density.

2.1. Experimental Studies. Al Issa and Macian [1] classified CCFL data according to the horizontal pipe length to diameter ratio into four groups: $\left(L_{H} / D\right)=0-5,5-10,10$ 25 , and $>40$. However, they did not clearly distinguish (1) locations of flooding and (2) onset of flooding or CCFL.

Minami et al. [8] observed three flooding locations using the $1 / 15$-scale model ( $50 \mathrm{~mm}$ diameter) shown in Figure 1; they were (A) the upper end of the inclined pipe (i.e., water inlet into the hot leg); (B) the gas inlet into the hot leg; (C) the horizontal pipe near the elbow. Flooding at (A) appeared only under large feed water flow rates in the process of increasing air flow rates, and onset of flooding conditions (i.e., test conditions of $J_{G}$ and $J_{\text {Lin }}$ at initiation of flooding) and CCFL characteristics under the quasisteady state (i.e., relationship between $J_{G}$ and $J_{L}$ ) after onset of flooding were different. When they were different, hysteresis between increasing and decreasing air flow rates appeared. Continuously increasing the air flow rate with flooding at (A) caused a flow pattern transition in the hot leg and flooding in $(\mathrm{C})$. Falling water flow rate $\left(J_{L}\right)$ under the quasisteady state was much smaller in flooding in (C) than that at (A). Flooding at (B) appeared only under relatively small feed water flow rates and large air flow rates in the process of increasing air flow rates, and it caused a flow pattern transition in the hot leg and flooding in (C). Under the quasisteady state after onset of flooding at (B), falling water flow rate became zero $\left(J_{L}=0\right)$ due to the 
TABLE 1: Test section dimensions and conditions.

\begin{tabular}{lcccccc}
\hline Reference & $D(\mathrm{~mm})$ & $L_{H} / D(-)$ & $L_{I} / D(-)$ & $\theta(\mathrm{deg})$ & Fluids & Pressure (MPa) \\
\hline Richter et al. [10] & 203.2 & 4.5 & 0 & 45 & Air-Water & 0.1 \\
Ohnuki et al. [11] & 25.4 & 9.1 & 1.2 & 50 & Air-Water & 0.1 \\
Mayinger et al. [7] & 750 & 9.0 & 1.1 & 50 & Stream-Water & $0.3,1.5$ \\
Geffraye et al. [12] & 351 & 7.5 & 3.0 & 50 & Air-Water & 0.1 \\
Navarro [9] & 54 & 9.3 & 1.9 & 50 & Air-Water & 0.1 \\
Minami et al. [8] & 50 & 8.4 & 1.2 & 50 & Air-Water & 0.1 \\
\hline
\end{tabular}

$D$ : diameter, $L_{H}$ : length of horizontal pipe, $L_{I}$ : length of inclined pipe, $\theta$ : angle of elbow.

large air flow rate at onset of flooding. Therefore, CCFL characteristics at the gas inlet were measured only under limited conditions. In the process of decreasing air flow rates, flooding in (C) continued, and deflooding conditions and CCFL characteristics agreed well with each other. The similar hysteresis between increasing and decreasing air flow rates was observed by Navarro [9]. In a PWR hot leg with the expansion of the inclined pipe, which was not simulated in Figure 1, flooding at (A) may not appear due to mitigation of CCFL with a large flow area and low gas velocity [4]. In most experimental studies, focus was on CCFL characteristics due to flooding in $(\mathrm{C})$.

Vallée et al. [3] selected experimental studies using the horizontal pipe length to diameter ratio of $\left(L_{H} / D\right)=7-10$ to compare CCFL characteristics in hot leg models. Major test conditions in previous studies are listed in Table 1. The empirical constant $C$ in (1) by Richter et al. [10] was about 0.7 and CCFL was mitigated compared with other cases where $C$ was about 0.6 , because the horizontal pipe length to diameter ratio $\left(L_{H} / D\right)$ was small. On the other hand, the empirical constant $C$ by Ohnuki et al. [11] was about 0.55 and CCFL became severe compared with other cases, because the diameter of $25.4 \mathrm{~mm}$ was too small. Therefore, CCFL data applicable to a PWR hot leg, which is our interest, are limited.

2.2. Numerical Studies. Wang and Mayinger [13] conducted two-dimensional analyses of countercurrent flows in the hot leg of the UPTF tests [7] using a Euler-Euler model. They gave boundary conditions at the inlet and outlet of the hot leg, which might affect the calculated flow patterns in the hot leg. Minami et al. [14] conducted numerical simulations using the CFD software FLUENT6.3.26 and an Euler-Euler model (i.e., two-fluid model) for countercurrent air-water tests using a 1/5-scale rectangular channel. Flow patterns in the hot leg were not reproduced by two-dimensional calculations due to effects of the wall friction but were successfully reproduced by three-dimensional calculations including the lower and upper tanks. Deendarlianto et al. [15] conducted numerical simulations using the CFD software ANSYS CFX 12.0 and a Euler-Euler model for countercurrent air-water tests using a 1/3-scale rectangular channel [3]. Good agreement with data was obtained for the transition process from flooding at the gas inlet to flooding in the horizontal section near the elbow. The computational grid consisted of 248,610 hexahedral elements and 281,076 nodes, and a long computer time was generally needed.
The objectives of our studies were to find a practical numerical method for sensitivity analyses and to evaluate effects of scale and fluid properties on CCFL characteristics in the hot leg. Based on the CCFL data from air-water tests with the diameter of $50 \mathrm{~mm}$ [8] and CCFL characteristics calculated for a full-scale model with the diameter of $750 \mathrm{~mm}$ using the two-fluid model, we proposed the following correlation for low pressures below $0.3 \mathrm{MPa}$ [4]:

$$
\left(J_{G}^{*}\right)^{1 / 2}=0.608-0.238\left(J_{L}^{*}\right)^{1 / 2}-1.28\left(J_{L}^{*}\right) .
$$

Figure 2 compares (3) with CCFL data listed in Table 1 and values calculated by the two-fluid model. The correlation by Navarro [9], derived from air-water tests (54 $\mathrm{mm}$ diameter), was very close to (3). There were no significant differences between CCFL characteristics obtained under the conditions of $7.5 \leq L / D \leq 9.3$ (cf. Table 1) and $50 \mathrm{~mm} \leq D_{h} \leq$ $750 \mathrm{~mm}$. In the UPTF tests, the diameter of the hot leg was $D=750 \mathrm{~mm}$, and the hydraulic diameter in the region with the ECC (emergency core cooling) injection tube was $D_{h}=650 \mathrm{~mm}$. In Figure 2, CCFL characteristics at $0.3 \mathrm{MPa}$ evaluated using $D_{h}=650 \mathrm{~mm}$ in (2) are shown. As shown in Figure 2(b), the two-fluid model reproduced CCFL characteristics under low pressure conditions using the same correlation for interfacial drag coefficients. The twofluid model, however, greatly underestimated falling water flow rates at $1.5 \mathrm{MPa}$ compared with the UPTF data [7] at $1.5 \mathrm{MPa}$.

In order to evaluate effects of fluid properties on CCFL characteristics, we improved the computational grid and schemes in the VOF method [6] and compared the CCFL characteristics calculated for full scale conditions with the UPTF data [7] at 1.5 MPa. Good agreement was obtained between them. In order to fit the calculated falling water flow rate with one UPTF data point at $1.5 \mathrm{MPa}$; however, the maximum value of the turbulent viscosity ratio was changed from the default value of $10^{5}$ in FLUENT6.3.26 to $10^{4}$ [6]. Therefore, the applicability of the VOF method to different fluid properties should be confirmed.

In this paper, we first did numerical simulations for fullscale air-water conditions ( $750 \mathrm{~mm}$ diameter), and compared the calculated CCFL characteristics with (3) to evaluate the applicability of the VOF method to different fluid properties. And then, to evaluate applicability of the VOF method to a different scale, we did numerical simulations for the 1/15scale air-water tests with the diameter of $50 \mathrm{~mm}$ [8]. 

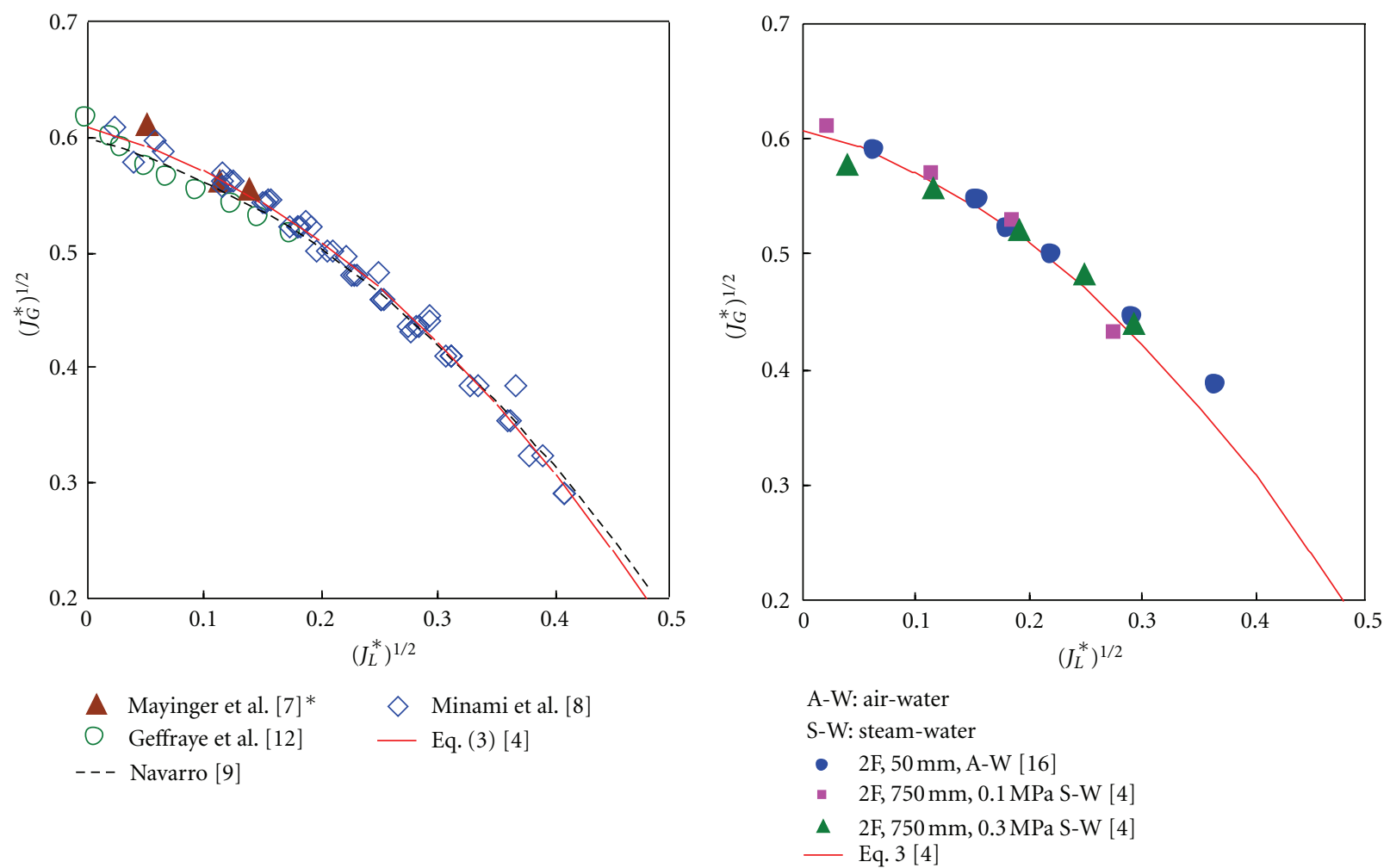

(a) Comparison of (3) with CCFL data (*steam-water at $0.3 \mathrm{MPa}$ others: air-water)

FIGURE 2: CCFL characteristics.

\section{Simulation Method}

In numerical simulations, the VOF method implemented in the CFD software FLUENT6.3.26 was used. The computational grid and schemes we used were the same as those in our previous report [6].

3.1. Computational Grid. Figure 3 shows the computational grid for the 1/15-scale hot leg model shown in Figure 1, which was reduced from the computational grid for a fullscale PWR hot leg [6]. Because velocity distributions of gas and liquid at both ends of the hot leg affect hydraulic behavior, the calculation region included the lower tank simulating the upper plenum in the reactor vessel and the upper tank simulating the SG inlet plenum. The expansion of the inclined pipe was not simulated in the experimental apparatus but was simulated in the grid shown in Figure 3. There were 299 calculation cells in the cross-section of the hot leg, and about 59,000 calculation cells in total. The diameter of the hot leg and the length of the horizontal pipe were $D=50 \mathrm{~mm}$ and $L_{H}=420 \mathrm{~mm}\left(L_{H} / D=8.4\right)$. The length of the tapered section was not included in the length of the horizontal pipe. Gas was supplied from the side wall into the lower tank and flowed into the upper tank through the hot leg. Water was supplied from the bottom of the upper tank. Some water gravitationally flowed into the lower tank through the hot leg. The water flow rate through the hot leg was calculated from the increasing rate of water volume in

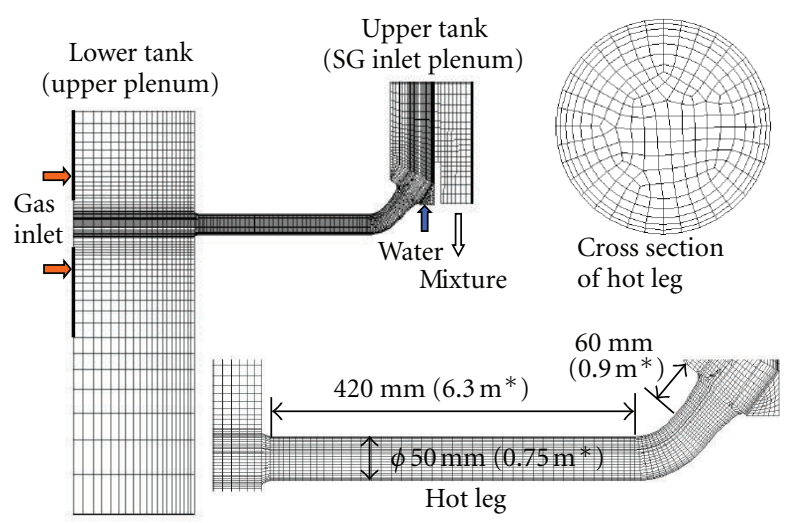

Figure 3: Computational grid (*full scale).

the lower tank. The boundary condition of constant velocity was used at the inlets of gas and water, and the boundary condition of constant pressure was used at the outlet of the gas-water mixture.

3.2. Computational Schemes. The standard $k-\varepsilon$ turbulent model was used for the gas and liquid phases. On wall surfaces, conditions of nonslip and the standard wall function were used. Momentum, volume fraction, turbulent kinetic energy, and turbulent dissipation rate of the gas and liquid phases were calculated using the first-order upwind 


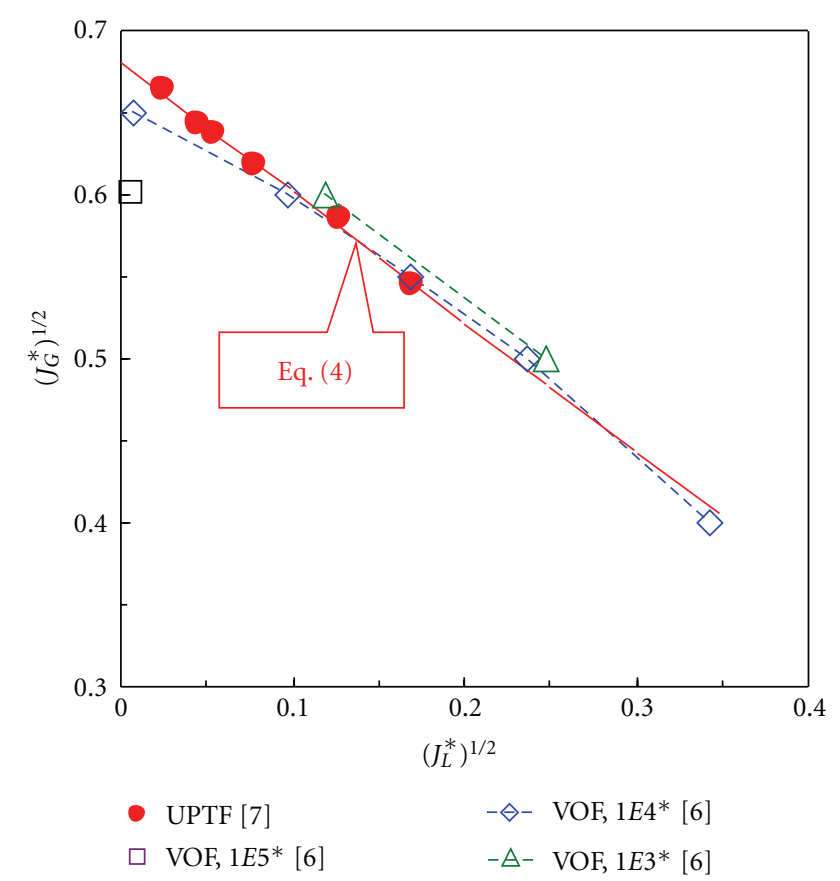

Figure 4: CCFL characteristics at $1.5 \mathrm{MPa}\left({ }^{*}\right.$ maximum turbulent viscosity ratio).

scheme. For the pressure-velocity coupling, the PISO method implemented in FLUENT6.3.26 and the noniterative time advancement with the neighbor correction of 3 were used. The variable time step was used. The time step was on the order of $0.1 \mathrm{~ms}$ for low pressures. In order to fit the calculated falling water flow rate with one UPTF data point at $1.5 \mathrm{MPa}$, the maximum value of the turbulent viscosity ratio was changed from the default value of $10^{5}$ in FLUENT6.3.26 to $10^{4}[6]$.

\section{Calculated Results}

Numerical simulations for full-scale air-water conditions (750 $\mathrm{mm}$ diameter) were first conducted, and the calculated CCFL characteristics were compared with (3) to evaluate the applicability of the VOF method to different fluid properties. And then, numerical simulations for the 1/15-scale airwater tests ( $50 \mathrm{~mm}$ diameter) [8] were conducted to evaluate applicability of the VOF method to a different scale.

4.1. Full-Scale Condition Results. The maximum value of the turbulent viscosity ratio is $10^{5}$ in the default values of FLUENT6.3.26. However, the maximum value of $10^{4}$ was used to get good agreement with the UPTF data [7] at $1.5 \mathrm{MPa}$ as shown in Figure 4. VOF calculations were done for steamwater flows at $1.5 \mathrm{MPa}$ under PWR full-scale conditions with the diameter of $0.75 \mathrm{~m}$ [6]. For UPTF data, the hydraulic diameter of $D_{h}=0.65 \mathrm{~m}$ in the region with the ECC injection tube was used in (2) because flooding might occur in the region. CCFL characteristics at $1.5 \mathrm{MPa}$ were fitted by

$$
\left(J_{G}^{*}\right)^{1 / 2}=0.68-0.79\left(J_{L}^{*}\right)^{1 / 2} .
$$

From the results in Figure 4, the maximum value of $10^{4}$ was used for the turbulent viscosity ratio in the following VOF calculations.

In order to evaluate capability to predict effects of fluid properties on CCFL characteristics, VOF calculations were conducted for air-water conditions at $0.1 \mathrm{MPa}$, where many experiments simulating a PWR hot leg have been carried out. Figure 5 compares flow patterns calculated by the VOF method with a flow pattern observed in the $1 / 15$ scale air-water tests [8]. Under flooding conditions in the tests, the water flow rate was restricted at the elbow side of the horizontal pipe. In the elbow and inclined pipe, large waves with droplets periodically flowed upward, water flowed downward from the upper tank, and recirculation of water with bubbles and droplets formed. Therefore, the observed flow pattern fluctuated in the elbow and inclined pipe. The calculation conditions were for air-water in a fullscale hot leg and different from the test conditions. However the calculated flow patterns were similar to the observed flow pattern. Comparing with the 1/15-scale tests, gas volumetric fluxes $J_{G}$ were larger due to a large diameter. Stable stratified flow formed in the horizontal pipe because small waves could not be calculated with the rather large calculation cells used. A large wave periodically appeared near the elbow and the water flow rate was restricted there. With increasing $J_{G}$, water depth became shallow in the horizontal section.

Figure 6(a) shows the calculated water volume in the lower tank after the quasisteady state, which was used to obtain the time-averaged water flow rate through the hot leg. Figure 6(b) compares the calculated CCFL characteristics with (3) for low pressure conditions. The calculated results agreed very well with (3) except for $\left(J_{G}^{*}\right)^{1 / 2}=0.5$, where the falling water flow rate was underestimated. The results showed capability to predict effects of fluid properties on CCFL characteristics and confirmed that CCFL characteristics in the Wallis diagram were mitigated under $1.5 \mathrm{MPa}$ steam-water conditions comparing with air-water flows at $0.1 \mathrm{MPa}$.

4.2. Standard $k-\varepsilon$ Turbulent Model Results for the 1/15Scale Air-Water Tests. Figure 7 shows results calculated using the standard $k-\varepsilon$ turbulent model. Figure 7 (a) shows the calculated water volume in the lower tank simulating the upper plenum after establishment of the quasisteady state, which was used to obtain the time-averaged water flow rate through the hot leg. The maximum value of the turbulent viscosity ratio was $10^{4}$. The results during the initial 5-10 s of the calculation were not used because they included transient effects after the change of calculation conditions. Figure $7(\mathrm{~b})$ compares calculated CCFL characteristics with test data [8]. The falling water flow rates $\left(J_{L}^{*}\right)$ were greatly underestimated. Even when the maximum value of the turbulent viscosity ratio was reduced to $10^{3}$, the calculated $\left(J_{L}^{*}\right)$ did not change.

4.3. Laminar Model Results for the 1/15-Scale Air-Water Tests. As shown in Figure $7(\mathrm{~b})$, the standard $k-\varepsilon$ turbulent model greatly underestimated the falling water flow rates $\left(J_{L}^{*}\right)$. Therefore, the laminar model was used. 


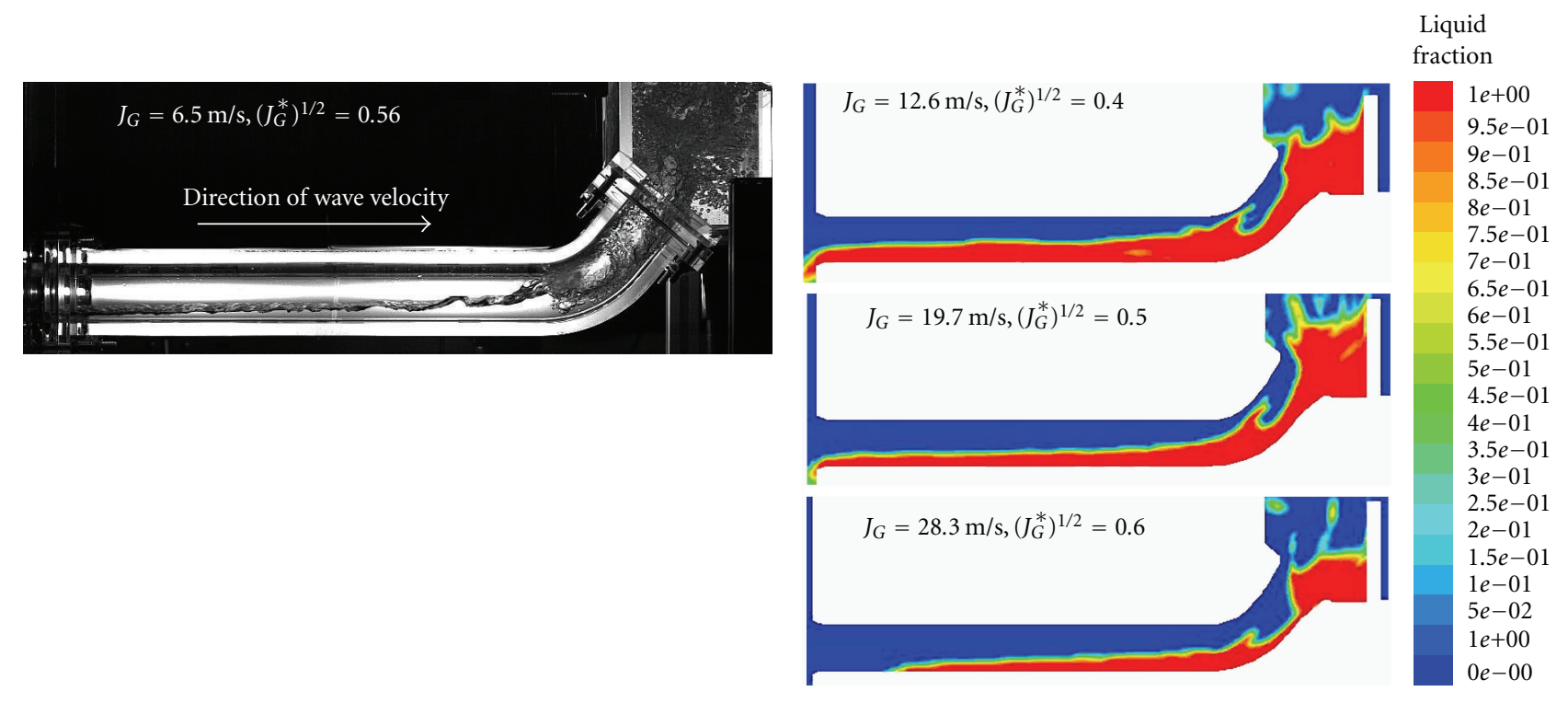

(a) $\mathrm{D}=50 \mathrm{~mm}$, air-water test [8]

(b) $D=750 \mathrm{~mm}$, air-water at $0.1 \mathrm{MPa}$

FIGURE 5: Flow patterns.

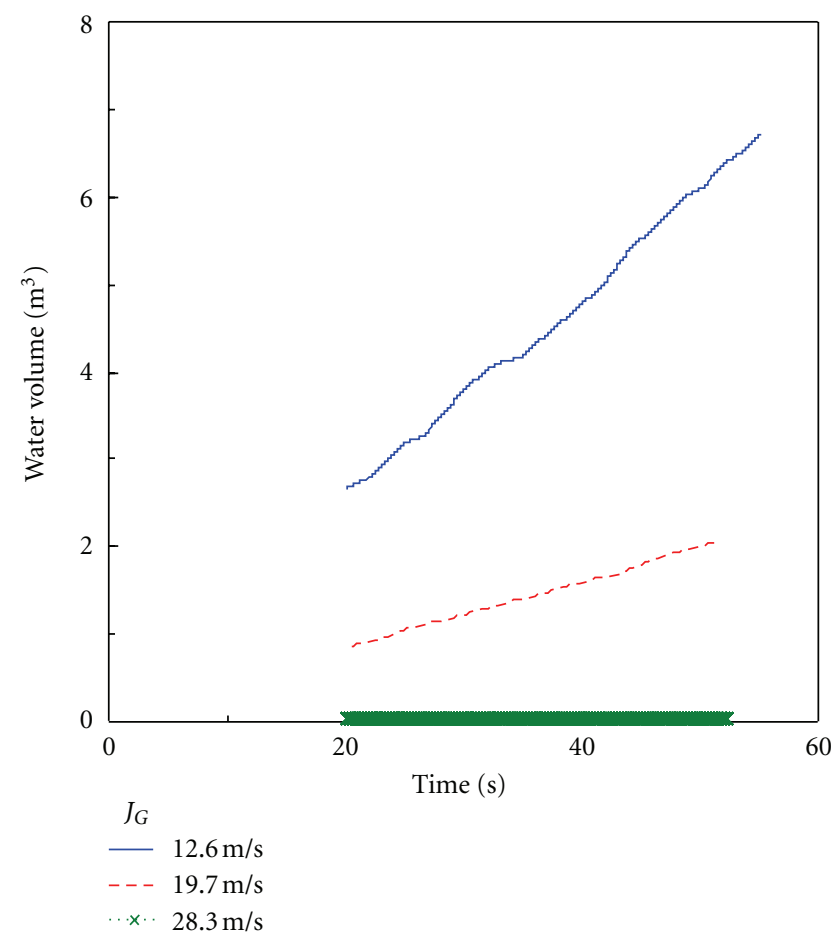

(a) Water volume in the lower tank (0.1 MPa, air-water)

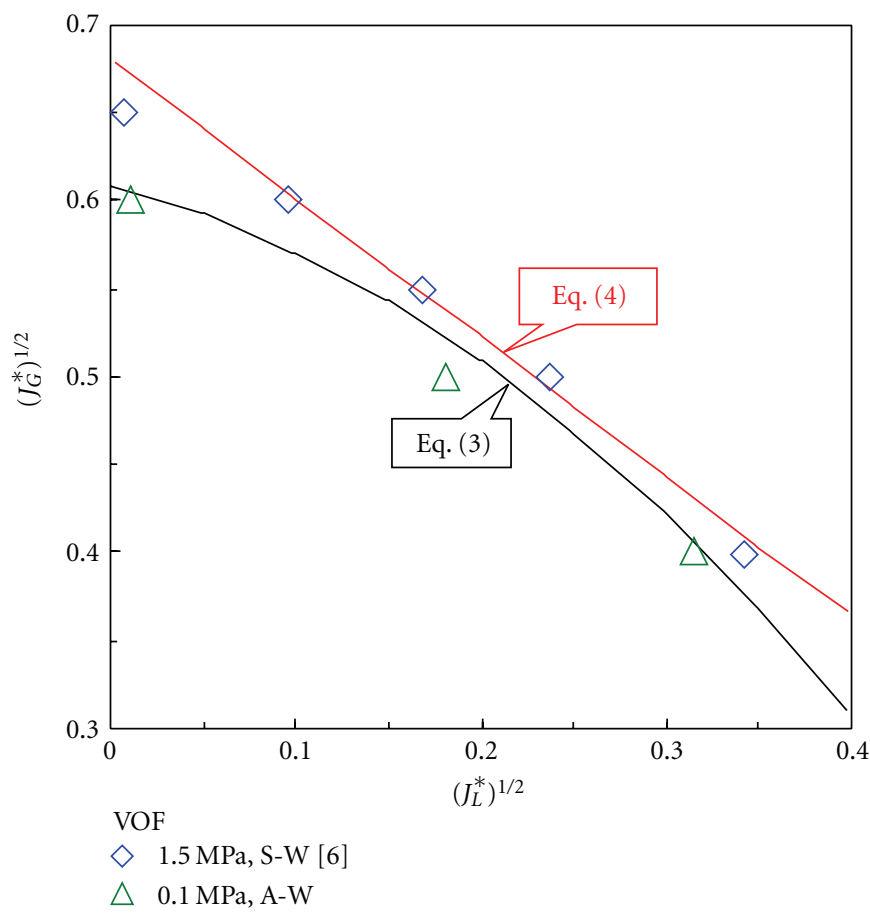

(b) CCFL characteristics (A-W: air-water, S-W: steam-water)

FIgURE 6: Results calculated for the full-scale hot leg.

Figure 8 shows flow patterns calculated by the VOF method. The calculated flow patterns were similar to the observed flow patterns shown in Figure 5(a). Because small waves could not be captured with the rather large calculation cells used, stratified flow formed in the horizontal pipe, but water near the gas-liquid interface flowed toward the elbow.
A large rolling wave periodically appeared near the elbow and the water flow rate was restricted there. The gas-liquid interface in the horizontal pipe fluctuated and it caused fluctuation of the falling water flow rate through the hot leg.

Figure 9 shows results calculated using the laminar model. Figure 9(a) shows the calculated water volume in the 


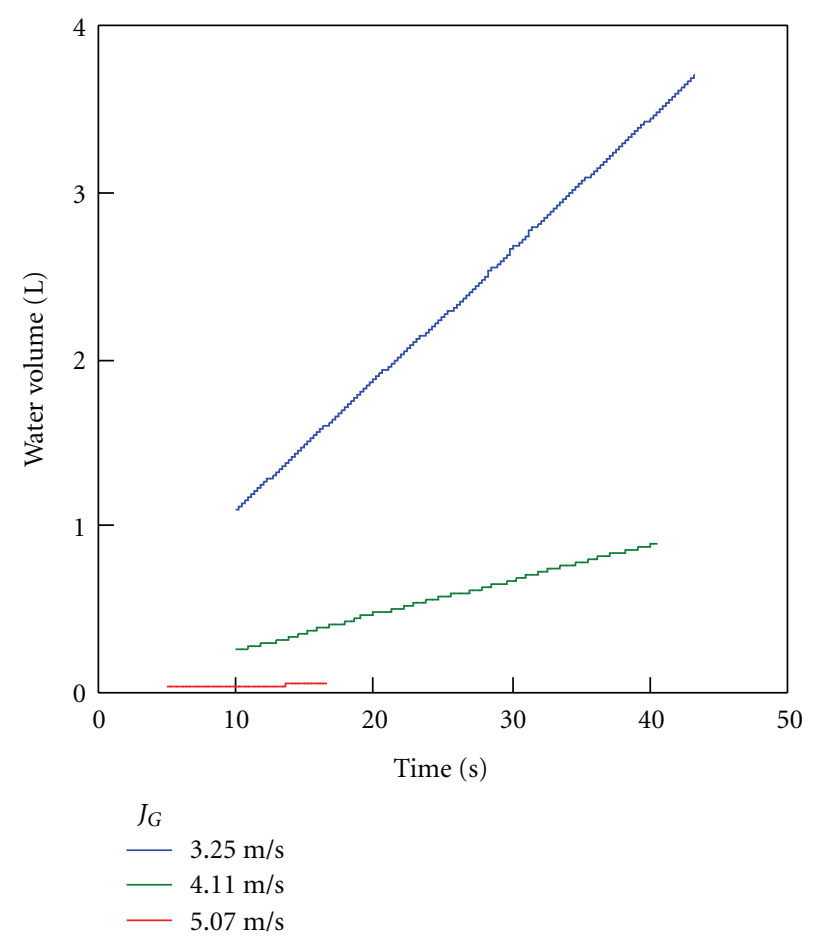

(a) Water volume in the lower tank (maximum turbulent viscosity ratio $\left.=10^{4}\right)$

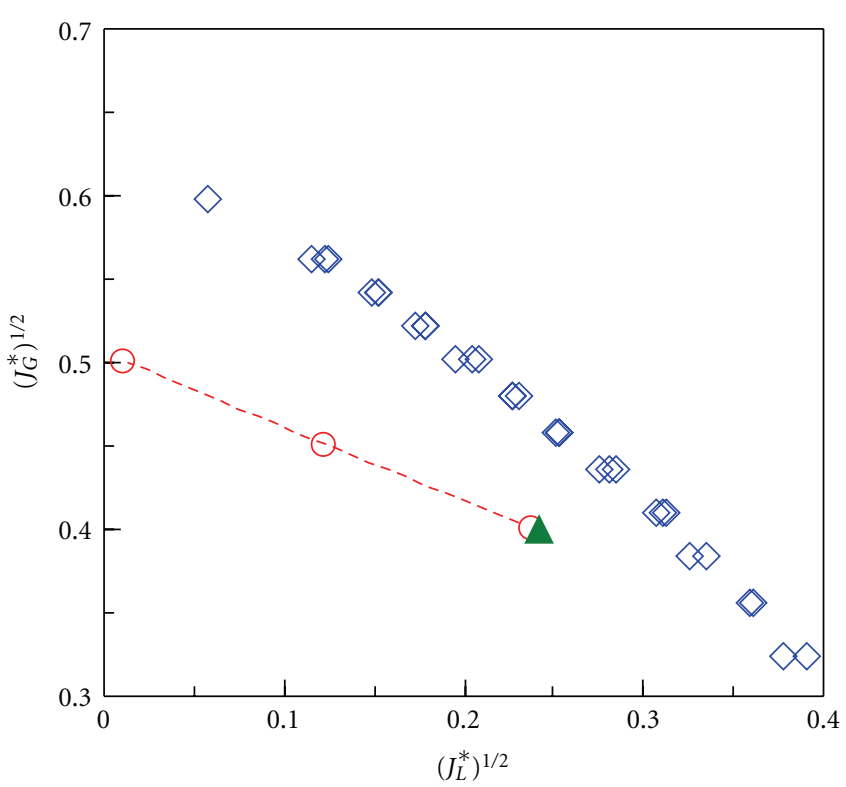

$\diamond$ Data $[8]$

$-\Theta-$ VOF, $1 E 4^{*}$

$-\mathrm{VOF}, 1 E 3^{*}$

(b) CCFL characteristics $(*$ maximum turbulent viscosity ratio $)$

FIGURE 7: Results calculated using the standard $k-\varepsilon$ turbulent model for the $1 / 5$-scale tests $(D=50 \mathrm{~mm}$, air-water).

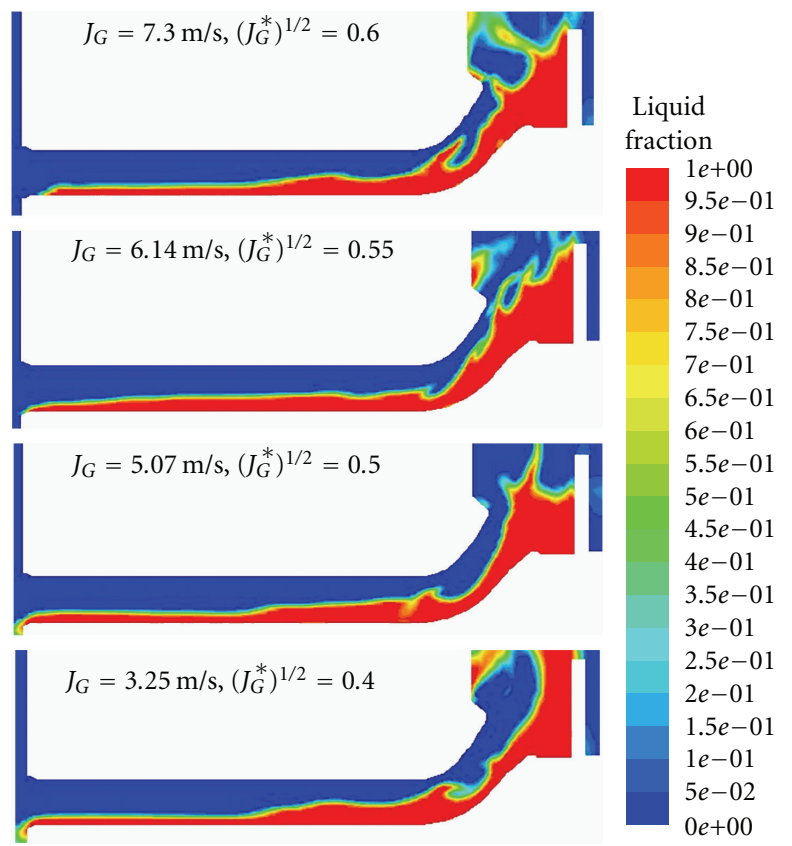

Figure 8: Flow patterns for the 1/5-scale tests (laminar model).

lower tank, which fluctuated due to fluctuation of the gasliquid interface in the horizontal pipe. The results during the initial $10 \mathrm{~s}$ of the calculation were not used for CCFL characteristics because they included transient effects after the change of calculation conditions. Figure 9(b) compares calculated CCFL characteristics with test data [8] and values calculated by the two-fluid model [16]. The falling water flow rates $\left(J_{L}^{*}\right)$ calculated by the VOF method with the laminar model agreed well with the test data and calculated results of the two-fluid model. 


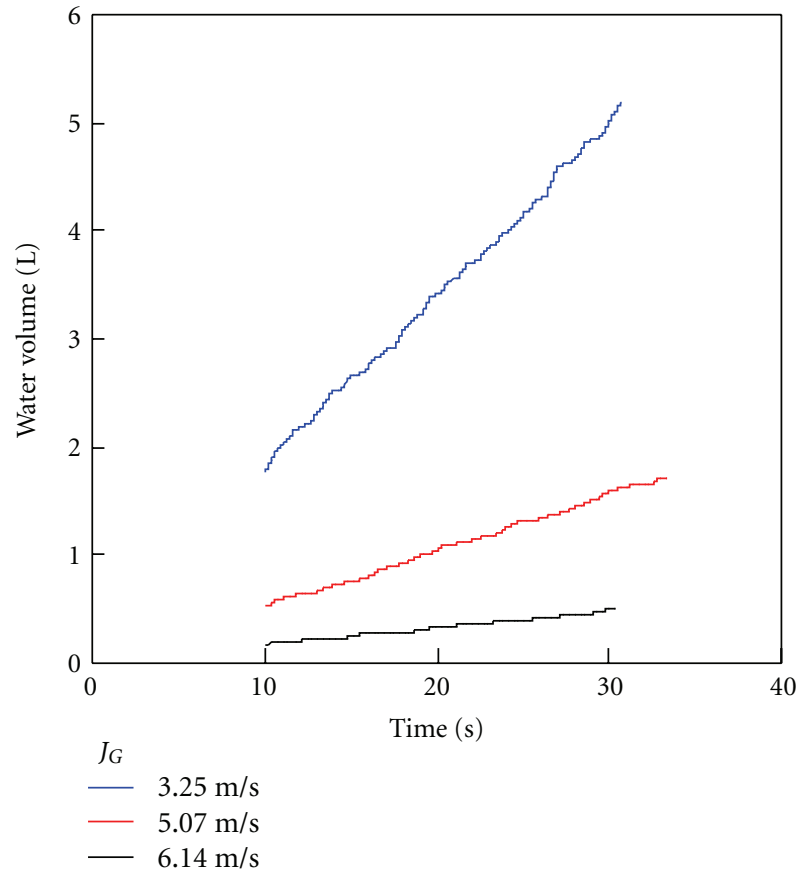

(a) Water volume in the lower tank (VOF, laminar model)

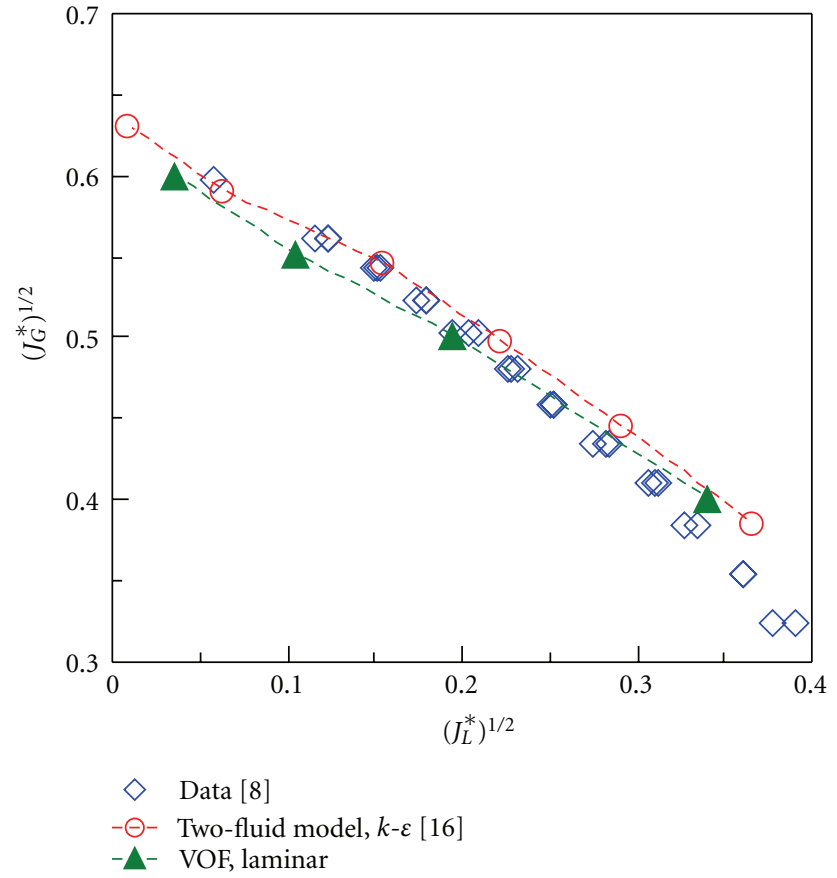

(b) CCFL characteristics

FIgURE 9: Results calculated using the laminar model for the $1 / 5$-scale tests ( $D=50 \mathrm{~mm}$, air-water).

TABLE 2: Summary of CCFL prediction.

\begin{tabular}{lccc}
\hline Shape and scale & Size & Two-fluid* & VOF: remarks \\
\hline $1 / 5$ rectangular & $H=150 \mathrm{~mm}$ & $\bigcirc(-)[14]$ & $\bigcirc(\bigcirc): k-\varepsilon\left(\mathrm{TVR}=10^{5}\right)[5]$ \\
$1 / 3$ rectangular & $H=250 \mathrm{~mm}$ & $\bigcirc(\triangle)[17]$ & $\Delta(\bigcirc): k-\varepsilon\left(\mathrm{TVR}=10^{5}\right)[17]$ \\
$1 / 15$ circular & $D=50 \mathrm{~mm}$ & $\odot(-)[16]$ & $\odot(-):$ laminar $[\mathrm{p}]$ \\
Full scale & $D=750 \mathrm{~mm}$ & $\odot(\times)[4]$ & $\odot(\odot): k-\varepsilon\left(\mathrm{TVR}=10^{4}\right)[\mathrm{p}]$ \\
\hline
\end{tabular}

${ }^{*}$ Standard $k-\varepsilon$ turbulent model, maximum turbulent viscosity ratio (TVR) $=10^{5}$,

$D$ : diameter, $H$ : height of rectangular channel,

(๐): very good, $\bigcirc$ : good, $\Delta$ : poor, $\times$ : very poor, —: not available,

( ): effects of fluid properties, []: references, [p]: present study.

4.4. Discussion. The standard $k-\varepsilon$ turbulent model gave a good CCFL prediction for full-scale hot leg conditions as shown in Figure 6(b). For 1/15-scale conditions, however, it greatly underestimated the falling water flow rates, and the laminar model gave a better CCFL prediction. Figure 10 shows the calculated Reynolds numbers of gas and liquid phases, which are defined by

$$
\operatorname{Re}_{k}=\frac{J_{k} D}{\nu_{k}}, \quad(k=G \text { or } L),
$$

where $v\left(\mathrm{~m}^{2} / \mathrm{s}\right)$ is the kinematic viscosity. The gas phase was turbulent in both the full scale and 1/15 scale. The liquid phase was turbulent except at low $J_{L}$ in the full scale conditions, but it was laminar except at high $J_{L}$ in the 1/15scale conditions. This may be related to why the laminar model gave the better CCFL prediction for the 1/15-scale conditions. On the other hand, however, in the two-fluid model, the standard $k-\varepsilon$ turbulent model gave a good CCFL prediction for both the $1 / 15$-scale and full-scale conditions as shown in Figure 2(b).
Table 2 summarizes results of the CCFL prediction. The two-fluid model with the standard $k-\varepsilon$ turbulent model gave good CCFL prediction for effects of shape and scale $[4,14,16,17]$. Its prediction was very good for circular channels, but poor or very poor for effects of fluid properties. Under large gas density conditions, it greatly underestimated the falling water flow rates. On the other hand, the VOF method gave good CCFL prediction for effects of fluid properties $[5,17]$. However, it was not suitable for circular channels, and the flow model should be changed to get good agreement with CCFL data. Table 2 indicates that suitable calculation models and conditions should be selected to get good agreement with data for each scale.

\section{Conclusions}

In order to evaluate applicability of the VOF method to different fluid properties and a different scale, we did numerical simulations for full-scale air-water conditions 


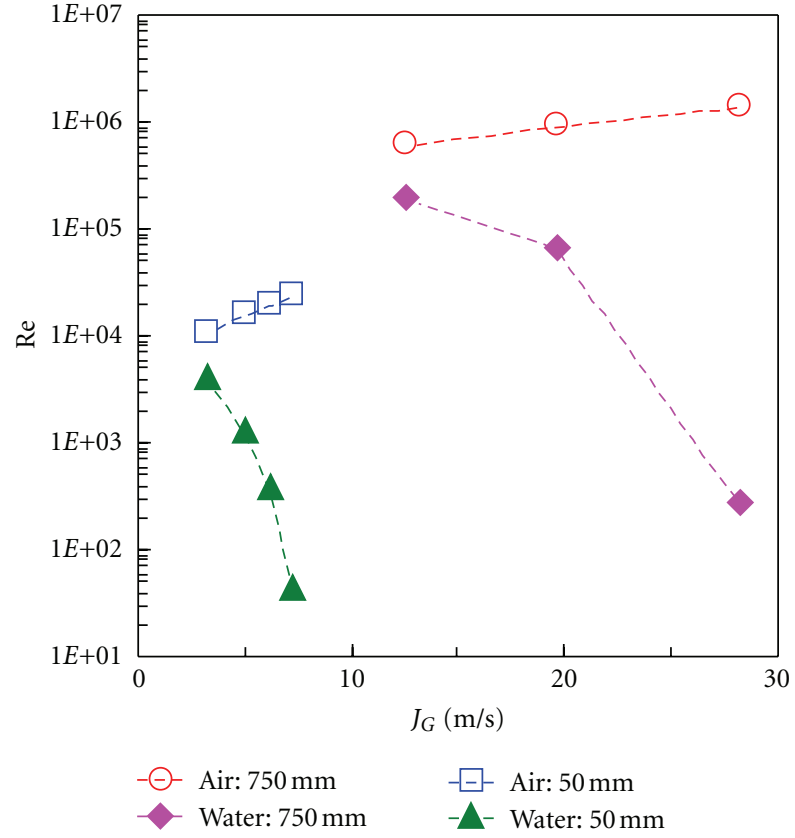

Figure 10: Reynolds numbers.

(750 $\mathrm{mm}$ diameter) and the $1 / 15$-scale air-water tests $(50 \mathrm{~mm}$ diameter), respectively.

The results calculated using the standard $k-\varepsilon$ turbulent model for full-scale conditions agreed well with CCFL data, and confirmed that CCFL characteristics in the Wallis diagram were mitigated under $1.5 \mathrm{MPa}$ steam-water conditions comparing with air-water flows at $0.1 \mathrm{MPa}$.

The results calculated using the standard $k-\varepsilon$ turbulent model for the $1 / 15$-scale air-water tests greatly underestimated the falling water flow rates. Therefore, a laminar flow model was used, and the calculated results agreed well with the CCFL data. This indicated that suitable calculation models and conditions should be selected to get good agreement with data for each scale.

\section{References}

[1] S. Al Issa and R. Macian, "A review of CCFL phenomenon," Annals of Nuclear Energy, vol. 38, no. 9, pp. 1795-1819, 2011.

[2] G. B. Wallis, One-Dimensional Two-Phase Flow, McGraw Hill, New York, NY, USA, 1969.

[3] C. Vallée, T. Seidel, D. Lucas, A. Tomiyama, and M. Murase, "Comparison of countercurrent flow limitation experiments performed in two different models of the hot leg of a pressurized water reactor with rectangular cross section," Journal of Engineering for Gas Turbines and Power, vol. 133, no. 5, article 052917, 2011.

[4] I. Kinoshita, M. Murase, Y. Utanohara, N. Minami, and A. Tomiyama, "Numerical simulation of countercurrent gasliquid flow in a PWR hot leg under reflux cooling," Journal of Nuclear Science and Technology, vol. 47, no. 10, pp. 963-972, 2010.

[5] I. Kinoshita, M. Murase, T. Nariai, and A. Tomiyama, "Countercurrent gas-liquid flow in a rectangular channel simulating a PWR hot leg (3) evaluation of effects of fluid properties using
VOF method," Japanese Journal of Multiphase Flow, vol. 24, no. 4, pp. 445-453, 2010 (Japanese).

[6] M. Murase, I. Kinoshita, C. Yanagi et al., "Numerical simulation of countercurrent gas-liquid flow in a PWR hot leg using VOF method," in Proceedings of the 14th International Topical Meeting on Nuclear Reactor Thermal-hydraulics (NURETH14067 '11), Toronto, Canada, September 2011.

[7] F. Mayinger, P. Weiss, and K. Wolfert, "Two-phase flow phenomena in full-scale reactor geometry," Nuclear Engineering and Design, vol. 145, no. 1-2, pp. 47-61, 1993.

[8] N. Minami, D. Nishiwaki, T. Nariai, A. Tomiyama, and M. Murase, "Countercurrent gas-liquid flow in a PWR hot leg under reflux cooling (I) air-water tests for 1/15-scale model of a PWR hot leg," Journal of Nuclear Science and Technology, vol. 47, no. 2, pp. 142-148, 2010.

[9] M. A. Navarro, "Study of countercurrent flow limitation in a horizontal pipe connected to an inclined one," Nuclear Engineering and Design, vol. 235, no. 10-12, pp. 1139-1148, 2005.

[10] H. J. Richter, G. B. Wallis, K. H. Carter, and S. L. Murphy, Deentrainment and Countercurrent Air-water Flow in a Model PWR Hot-leg, NRC-0193-9, U. S. Nuclear Regulatory Commission, 1978.

[11] A. Ohnuki, H. Adachi, and Y. Murao, "Scale effects on countercurrent gas-liquid flow in a horizontal tube connected to an inclined riser," Nuclear Engineering and Design, vol. 107, no. 3, pp. 283-294, 1988.

[12] G. Geffraye, P. Bazin, P. Pichon, and A. Bengaouer, "CCFL in hot legs and steam generators and its prediction with the CATHARE code," in Proceedings of the 7th International Topical Meeting on Nuclear Reactor Thermal Hydraulics (NURETH7 '95), Saratoga Springs, NY, USA, September 1995.

[13] M. J. Wang and F. Mayinger, "Simulation and analysis of thermal-hydraulic phenomena in a PWR hot leg related to SBLOCA," Nuclear Engineering and Design, vol. 155, no. 3, pp. 643-652, 1995.

[14] N. Minami, M. Murase, D. Nishiwaki, and A. Tomiyama, "Countercurrent gas-liquid flow in a rectangular channel simulating a PWR hot leg (2) analytical evaluation of countercurrent flow limitation," Japanese Journal of Multiphase Flow, vol. 22, no. 4, pp. 413-422, 2008 (Japanese).

[15] Deendarlianto, T. Höhne, D. Lucas, and C. Vallée, "Numerical simulation of air-water counter-current two-phase flow in a model of the hot-leg of a pressurized water reactor (PWR)," in Proceedings of the 7th International Conference on Multiphase Flow (ICMF '10), Tampa, Fla, USA, May 2010.

[16] N. Minami, M. Murase, and A. Tomiyama, "Countercurrent gas-liquid flow in a PWR hot leg under reflux cooling (II) numerical simulation of 1/15-scale air-water tests," Journal of Nuclear Science and Technology, vol. 47, no. 2, pp. 149-155, 2010.

[17] Y. Utanohara, I. Kinoshita, M. Murase, D. Lucas, C. Vallée, and A. Tomiyama, "Numerical simulations for steam-water CCFL tests using the $1 / 3$ scale rectangular channel simulating a PWR hot leg," Nuclear Engineering and Design. In Press. 

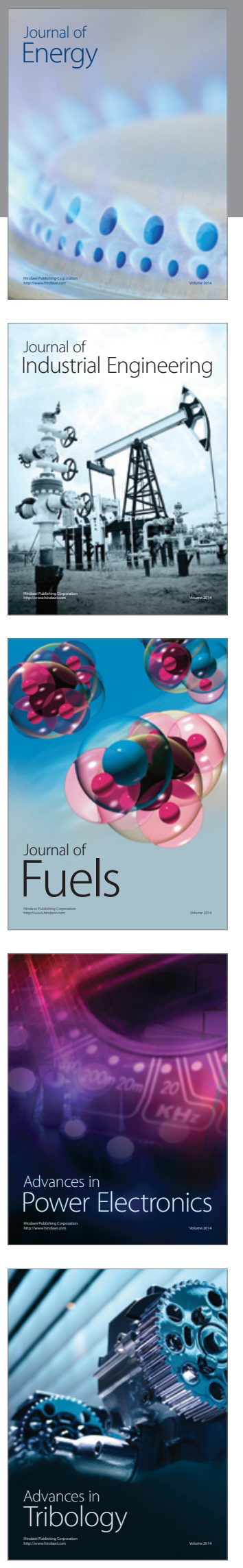
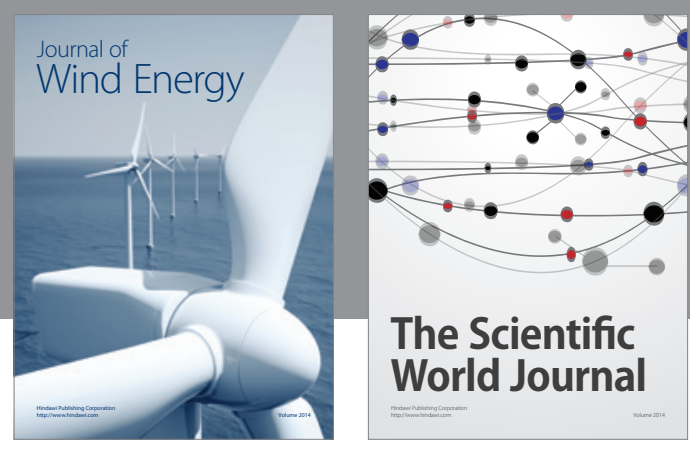

The Scientific World Journal

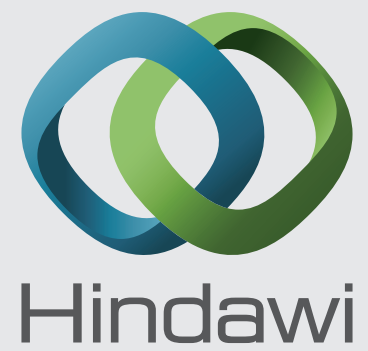

Submit your manuscripts at http://www.hindawi.com
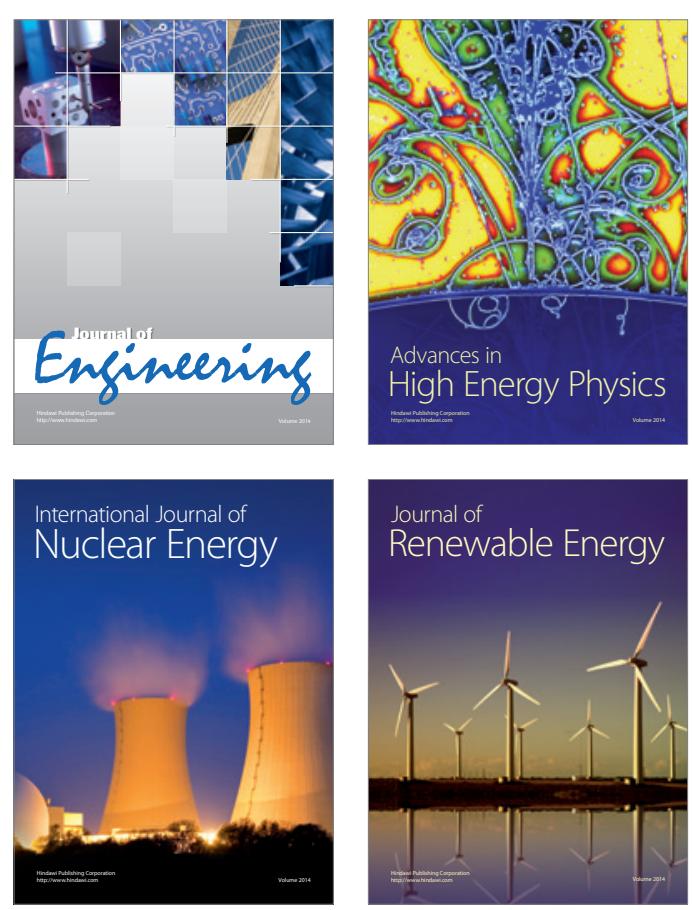

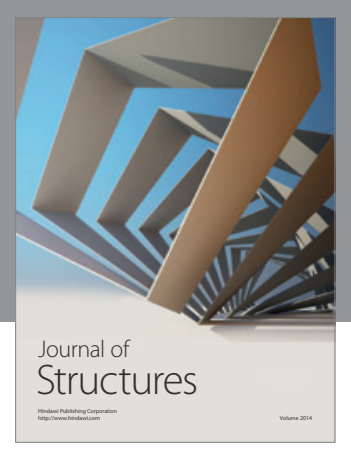

Rotating
Mechinery
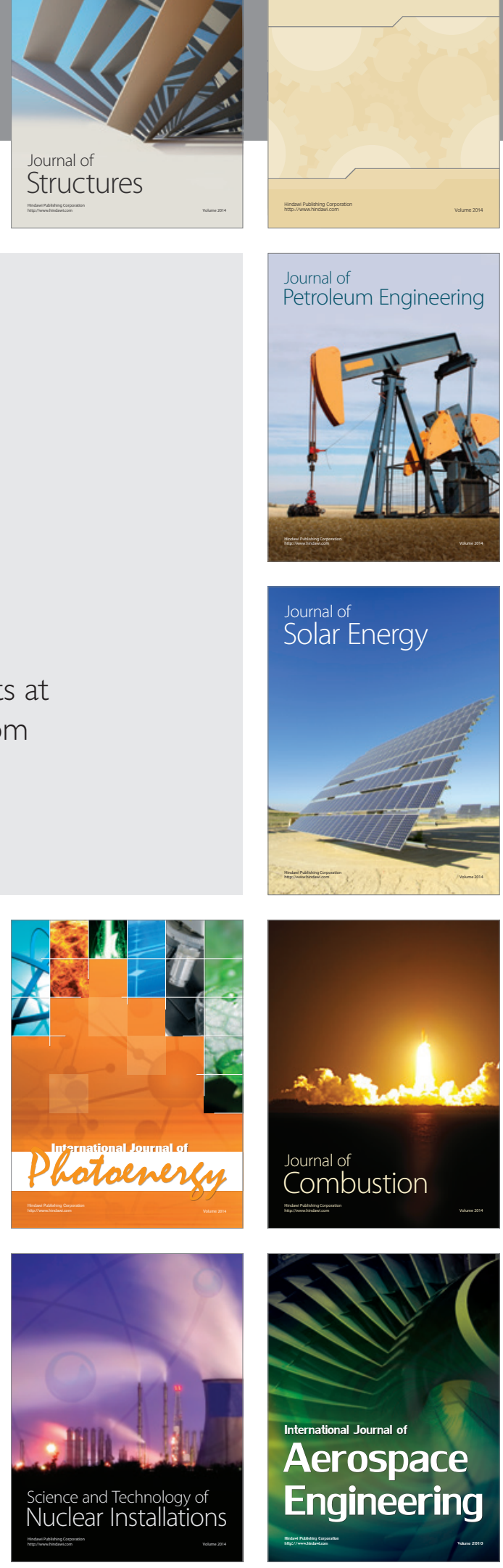